\title{
Optimization of workcell layouts in a mixed-model assembly line environment
}

\author{
Erica Klampfl · Oleg Gusikhin · Giuseppe Rossi
}

Published online: 30 April 2007

(C) Springer Science+Business Media, LLC 2007

\section{Erratum to: Int J Flex Manuf Syst DOI: $10.1007 / \mathrm{s} 10696-006-9029-6$}

The following biographical information was omitted from the original article:

Oleg Y. Gusikhin is currently the Technical Leader of the Enterprise Information Systems Research group at the Ford Research and Innovation Center in Dearborn, Michigan. He holds a Ph.D. in Applied Mathematics and Computer Sciences from the St. Petersburg Institute of Informatics and Automation of Russian Academy of Sciences (1992) and an MBA from the University of Michigan, Ann Arbor (2004). Over the course of his career, Dr. Gusikhin has been active in several areas of Operations Research, Information Technology and Supply Chain Management both in academia and industry. He is a Certified Fellow in Production and Inventory Management from the American Production and Inventory Control Society and a Certified Enterprise Integrator from the Society of Manufacturing Engineers.

Erica Klampfl is currently a Technical Expert in the Supply Chain Management Research group at the Ford Research and Innovation Center in Dearborn, Michigan. She received a Ph.D. in Computational and Applied Mathematics from Rice University in 2001. Her research interests include operations research applications to automotive manufacturing, workplace efficiency, and supply chain management. She is an active member of INFORMS and SIAM.

The online version of the original article can be found at http://dx.doi.org/10.1007/s10696-006-9029-6

E. Klampfl $(\bowtie) \cdot$ O. Gusikhin · G. Rossi

Ford Research and Advanced Engineering, Supply Chain Management Research Group, Dearborn, MI, USA 